\title{
A 10-Year Survey of Severe Eye Injuries in Sport in Belgrade, Serbia 2000-2009
}

\author{
Miloš Jovanović ${ }^{1 *}$, Dragan Vuković ${ }^{1}$, Vesna Jakšić ${ }^{2}$, Miroslav Knežević ${ }^{1}$, Lepša Žorić ${ }^{2}$, \\ Miloš Mirković \\ ${ }^{1}$ Faculty of Medicine, University of Belgrade, Belgrade, Serbia; ${ }^{2}$ Faculty of Medicine, University of Kosovska Mitrovica, Kosovska \\ Mitrovica, Serbia. \\ Email: *milosjov@scnet.rs
}

Received January $23^{\text {rd }}, 2013$; revised February $24^{\text {th }}, 2013$; accepted March $15^{\text {th }}, 2013$

Copyright (C) 2013 Miloš Jovanović et al. This is an open access article distributed under the Creative Commons Attribution License, which permits unrestricted use, distribution, and reproduction in any medium, provided the original work is properly cited.

\begin{abstract}
Introduction: The eye injuries inflicted in different sport activities are relatively rare and depend upon the type of sport. They are more common in recreational sport activities. These injuries are generally minor but may be very severe and result in permanent vision impairment. One must be aware of the fact that these sport activities, either recreative or professional, are exercised by young people. Methods: All analyzed patients were hospitalized at the Clinic of Eye Diseases, Clinical Center of Serbia, Belgrade, for severe eye injuries which occurred in sport activities. The analyzed period included 10 years, from the beginning of 2000 to the end of 2009. Results: In this period, a total of 117 patients with eye injuries sustained in some of sport activities were hospitalized. There were 114 (97.5\%) injured males. Mean age of the injured was 25.8 years, and there were no individuals older than 50 years of age. Closed eyeball injures were reported in $96.6 \%$ and open injuries were seen in the remaining $3.4 \%$ of cases. During recreational sports, the eye injuries occurred in $76.1 \%$, in the school $-19.6 \%$, and in professional sport $-4.3 \%$ of the time. The injured individuals were as follows: pupils $-35.0 \%$, students $-17.9 \%$, workers $-22.2 \%$, clerks $-20.6 \%$ and professional players $-4.3 \%$ of cases. Upon completed treatment, visual acuity was normal in $77.8 \%$, subnormal in $16.2 \%$, impaired in $3.4 \%$ and amaurosis in $2.6 \%$ of cases.
\end{abstract}

Keywords: Eye Injuries; Sport Activities; Recreation; Eye Protection

\section{Introduction}

In the past decade, the incidence of sport eye injuries tended to have increasing growth $[1,2]$. Garrow, in 1923, reported that the sport eye injuries accounted only for $0.7 \%$ of all patients admitted for treatment of their eye injures in the Glasgow Royal Infirmary [3]. Canavan et al. in 1980 reported the incidence of sport eye injures of $4.1 \%$ [4], and Jones, in 1988, showed the increase of percentage to $25.1 \%$ [5], while in MacEwen's paper, 1989 , the proportion of sport eye injures was $42.2 \%$ [6]. At the beginning of 21 st century such percentage was decreased, and therefore, Barr et al., in their study in 2000 , reported the sport eye injury incidence of $12.5 \%$ [2], and in 2007 study by Len et al., such percent was $11 \%$ [7]. This paper analyzes the incidence, nature of injury and functional sequelae of sport injuries in Serbia in the first decade of our century.

\footnotetext{
"Corresponding author.
}

\section{Material and Methods}

The paper analyzed the patients who sustained the eye injuries in sport activities. Due to severity of eye injuries, they were all hospitalized and treated at the Clinic of Eye Diseases, Clinical Center of Serbia in Belgrade. The analyzed period of time was 10 years, from January 1, 2000 to December 31, 2009. Data from the Registry of in-patients of the Clinic of Eye Diseases, Clinical Center of Serbia in Belgrade were used in this investigation. Hospitalized injured patients played football, tennis, basketball, handball, water polo and paintball as recreational activities, in school at gym classes or as professional activities.

The following parameters were analyzed: age, site of injury, occupation, nature of the eye injury, as well as final visual acuity of the injured eye.

The objective of this investigation was to establish the frequency of the eye injuries in different sport activities, types of injury, final visual acuity and probable options 
of undertaking specific preventive measures.

\section{Results}

In the analyzed 10-year period (2000-2009), a total of 3206 patients were hospitalized at the Clinic of Eye Diseases, Clinical Center of Serbia in Belgrade, for serious mechanical injuries. Out of this number, 117 (3.6\%) patients sustained their eye injuries during some sport activities (Table 1). All but 3 injured were males; 2 girls had their eyes injured by tennis ball and the third girl was injured while playing the handball. The right eye was wounded in $70(59.8 \%)$ cases. There was no patient with simultaneous injuries of both eyes. In general, the injuries occurred in children and younger adults, and not after the age of fifty (Table 2). Mean age of the injured was 25.8 years.

Closed injuries were reported in $113(96.6 \%)$ patients and open injuries were evident in the remaining 4 (3.4\%) cases. In closed bulbar injuries, there were different damages of the intraocular structures, and in open injuries two cases manifested penetrating injuries and two other cases had rupture of the eye ball (Table 3 ).

The majority of injuries occurred in recreational sport activities-76.1\%, followed by school- $19.6 \%$ and in professional sports - only $4.3 \%$.

The occupation of the injured patients was different and with different percentage of involvement: pupils, students, workers, clerks, and professional players (Table 4).

Upon completed treatment, visual acuity was normal in $77.8 \%$, subnormal in $16.2 \%$, impaired vision in $3.4 \%$ and amaurosis in $2.6 \%$ of cases (Table 5).

\section{Discussion}

Our study showed that the percentage of sport eye inju-

Table 1. The number of the injuries in different sports.

\begin{tabular}{ccc}
\hline Sport & No. of sports & $\%$ \\
\hline Football & 95 & 81.2 \\
Tennis & 10 & 8.5 \\
Basketball & 4 & 3.4 \\
Paint ball & 4 & 3.4 \\
Water polo & 3 & 2.6 \\
Handball & 1 & 0.9 \\
Total & 117 & 100.0 \\
\hline
\end{tabular}

Table 2. Distribution by age of patients with sport eye injuries.

\begin{tabular}{ccccccc}
\hline Year & $0-9$ & $10-19$ & $20-29$ & $30-39$ & $40-49$ & Total \\
\hline $\begin{array}{c}\text { No. of } \\
\text { patients } \\
\%\end{array}$ & 3 & 42 & 39 & 22 & 11 & 117 \\
\hline
\end{tabular}

Table 3. Types of the sustained injuries.

\begin{tabular}{ccc}
\hline \multicolumn{1}{c}{ Injury } & No. & $\%$ \\
\hline Closed globe & 113 & 96.6 \\
Hyphaema & 96 & 82.1 \\
Iridodialysis & 17 & 14.6 \\
Subluxatio lentis & 9 & 7.7 \\
Cataract & 3 & 2.6 \\
Vitreous hemorrhage & 15 & 12.8 \\
Retinal hemorrhage and edema & 36 & 30.8 \\
Open globe & 4 & 3.4 \\
Penetrating & 2 & 1.7 \\
Rupture & 2 & 1.7 \\
Total & 117 & 100.0 \\
\hline
\end{tabular}

Table 4. Occupation of patients with the eye sport injuries.

\begin{tabular}{ccccccc}
\hline Profession & Pupil Student & \multicolumn{6}{c}{ orker } & Clerk & Professional player & Total \\
\hline $\begin{array}{c}\text { No. of } \\
\text { patients }\end{array}$ & 41 & 21 & 26 & 22.2 & 5 & 117 \\
$\%$ & 35.0 & 17.9 & 24 & 20.6 & 4.3 & 100.0 \\
\hline
\end{tabular}

Table 5. Final visual acuity (VA) of patients.

\begin{tabular}{ccc}
\hline Final VA & $\mathrm{N}_{0}$ of patients & $\%$ \\
\hline $20 / 25-20 / 20$ & 91 & 77.8 \\
$20 / 50-20 / 30$ & 19 & 16.2 \\
$1 \mathrm{~m}$ to $20 / 60$ & 4 & 3.4 \\
Amaurosis & 3 & 2.6 \\
\hline
\end{tabular}

ries on the territory of the city of Belgrade of $3.6 \%$ was significantly less in comparison to percentage of the same injuries reported by other authors [3-7]. There are several reasons for the aforementioned. The first reason is that, under current conditions in Serbia, the eye injuries occur most commonly in public places, at home and during work. In this way, an overall involvement of sport injuries has been reduced [8]. The second reason is that the indications for hospitalization are narrowed, and accordingly, a large number of sport eye injuries is managed on outpatient basis, and our study analyzed only sport eye injuries in hospitalized patients. The same reason for reduction of sport eye injuries was reported by other authors in their papers $[9,10]$. The third reason is a modification of population age structure. In today's Serbia, the percentage of adult young people has been continuously decreasing, and these young people are actually the individuals going in for sports. Unfortunately, better eye protection cannot be reported as the reason for lower percentage of eye injuries, because no protection devices, except in paintball, are generally used in our setting.

Football was the commonest cause of the eye injuries. Such cause was mentioned by other authors as well $[11,12]$. Football is the most popular sport in Serbia, being played 
in different professional leagues or more often, just for recreation purposes. That is why the eye injuries are more frequent in football players playing it for fun. Only three cases were reported among professional football players. In one case, the injury was caused by blow of the opponent player's elbow, resulting in bulbar rupture and amaurosis. Other two open (penetrating) wounds of the eyeball occurred in recreating football players, namely, one sustained it while falling down and hitting the eye against some prominent object on the ground and another in similar way, by some sharp object on the playground.

The second game by frequency of the eye injuries was tennis. Out of $10(8.5 \%)$ tennis injuries, seven was caused by racquet and three by ball. In all cases it was the question of contusion globe injuries. Regarding the basketball, the injuries were present in only 4 (3.4\%) of all intrahospitally-treated sport eye injuries. One of these injuries occurred in professional basketball player. Three injuries were reported in water polo, i.e. one in professional player, which was caused by blow of the opponent player and resulted in rupture of the globe. Only one patient with the eye injury was reported in case of handball. It was the contusion of the globe in a school-girl who sustained her injury during gym class.

Although all these aforementioned sports after football are relatively popular in Serbia, far lower percentage of the eye injuries in other sports than football is accounted for their lesser prevalence in recreational sport activity. Recently introduced sport — paintball — is played in Serbia only as recreation activity. Although adequate protective devices are provided by regulations, 4 very serious injuries were noted. All injuries occurred at the moment when players' goggles were off. In all 4 cases the patients were adults, and 2 of them sustained severe injuries with consequent loss of vision. One of these two patients was a surgeon whose loss of vision disabled him to continue with his surgical profession.

It is interesting that, during 10-year analyzed period, there was no hockey player or boxer, although these two sports represent activities with frequent eye injuries, what was also reported by other authors [13-15].

Opposite to high proportion of injuries in recreational sports, the reason for so small number of injuries in professional players lies in their well-coordinated team play, instructions given by their coaches and respect of the basic rules of game.

Eye protection measures of sport players analyzed in this study, other than paintball, are not provided by regulations and, therefore, they are not applied. Nevertheless, it does not mean that it is the issue not to be contemplated on in future.

\section{Conclusion}

The conclusion has been reached that the eye injuries during different sports mostly occurred in young people who exercised sport as recreation. In a largest number of cases, it was the question of contusion injuries of the globes with the damage of intraocular structures. Onethird of the injured had the impaired vision of the injured eye. For this reason, the prevention of injuries with strict respect of the rules of games and wearing of protection devices, if provided for specific game or sport, should be given preference.

\section{REFERENCES}

[1] C. J. MacEwen and G. R. McLatghie, "Eye Injuries in Sport," Scottish Medical Journal, Vol. 55, No. 2, 2010, pp. 22-24. doi:10.1258/rsmsmj.55.2.22

[2] A. Barr, P. S. Baines, P. Desai and C. J. MacEwen, "Ocular Sports Injuries: The Current Picture," British Journal of Sports Medicine, Vol. 34, No. 6, 2000, pp. 456-458.

[3] A. Garrow, "A Statistical Enquiry into 1000 Cases of Eye Injuries," British Journal of Ophthalmology, Vol. 7, 1923, pp. 65-80. doi:10.1136/bjo.7.2.65

[4] J. M. Canavan, M. J. O'Flaherry and D. B. Archer, "A 10-Year Survey of Eye Injuries in Northern Ireland 196776," British Journal of Ophthalmology, Vol. 64, No. 8, 1980, pp. 618-625. doi:10.1136/bjo.64.8.618

[5] N. P. Jones, "One Year of Severe Eye Injuries in Sport," Eye, Vol. 2, 1988, pp. 484-487. doi:10.1038/eye.1988.97

[6] C. J. MacEwen, "Eye Injuries: A Prospective Survey of 5671 Cases," British Journal of Ophthalmology, Vol. 73, No. 11, 1989, pp. 888-894. doi:10.1136/bjo.73.11.888

[7] T. Leivo, I. Puusaari and T. Mäkitie, "Sports-Related Eye Injuries: Floorball Endangers the Eyes of Young Players," Scandinavian Journal of Medicine \& Science in Sports, Vol. 17, No. 5, 2007, pp. 556-563.

[8] M. Jovanovic, I. Stefanovic and Z. Latkovic, "Mechanical Injuries of the Eye: Incidence, Structure and Possibilities for Prevention," Vojnosanitetski Pregled, Vol. 67, No. 12, 2010, pp. 983-990.

[9] D. R. May, F. P. Kuhn, R. E. Morris, C. D. Witherspoon, R. P. Danis, G. P. Matthews and I. Mann, "The Epidemiology of Serious Eye Injuries from the United States Eye Injury Registry," Graefe's Archive for Clinical and Experimental Ophthalmology, Vol. 238, No. 2, 2000, pp. 153-157. doi:10.1007/PL00007884

[10] P. Desai, C. J. McEwen, P. Baines and D. C. Minassian, "Epidemiology and Implications of Ocular Trauma Admitted to Hospital in Scotland," Journal of Epidemiology \& Community Helath, Vol. 50, No. 4, 1996, pp. 436-441. doi:10.1136/jech.50.4.436

[11] J. A. Capao Filipe, "Soccer (Football) Ocular Injuries: An Important Eye Health Problem," British Journal of Ophthalmology, Vol. 88, No. 2, 2004, pp. 159-160. doi:10.1136/bjo.2003.031518

[12] J. S. Kent, R. B. Eidsness, K. M. Colleaux and K. G. Romanchuk, "Indoor Soccer-Related Eye Injuries: Should Eye Protection Be Mandatory?" Canadian Journal of 
Ophthalmology, Vol. 42, No. 4, 2007, pp. 605-608. doi:10.3129/i07-093

[13] D. S. Morris, "Ocular Blunt Trauma: Loss of Sight from an Ice Hockey Injuri," British Journal of Sports Medicine, Vol. 40, No. 3, 2006, pp. 1-2. doi:10.1136/bjsm.2005.017889

[14] M. Bianco, A. S. Vaiano, F. Colella, F. Coccimiglio, M. Masetti, V. Palmieri, F. Focosi and P. Zeppilli, "Ocular
Complications of Boxing," British Journal of Sports Medicine, Vol. 39, No. 2, 2005, pp. 70-74. doi:10.1136/bjsm.2003.006643

[15] M. Hazar, M. Beyloroglu and M. Subasi, "Ophthalmological Findings in Elite Amateur Turkish Boxers," British Journal of Sports Medicine, Vol. 36, No. 6, 2002, pp. 428-430. doi:10.1136/bjsm.36.6.428 